\title{
Visual performance after the implantation of a new trifocal intraocular lens
}

\author{
Jérôme CVryghem ${ }^{1,2}$ \\ Steven Heireman ${ }^{1,2}$ \\ 'Brussels Eye Doctors, Brussels, \\ Belgium; ${ }^{2}$ Clinique Saint-Jean, \\ Brussels, Belgium
}

This article was published in the following Dove Press journal:

Clinical Ophthalmology

30 September 2013

Number of times this article has been viewed
Purpose: To evaluate the subjective and objective visual results after the implantation of a new trifocal diffractive intraocular lens.

Methods: A new trifocal diffractive intraocular lens was designed combining two superimposed diffractive profiles: one with +1.75 diopters (D) addition for intermediate vision and the other with $+3.50 \mathrm{D}$ addition for near vision. Fifty eyes of 25 patients that were operated on by one surgeon are included in this study. The uncorrected and best distance-corrected monocular and binocular, near, intermediate, and distance visual acuities, contrast sensitivity, and defocus curves were measured 6 months postoperatively. In addition to the standard clinical follow-up, a questionnaire evaluating individual satisfaction and quality of life was submitted to the patients.

Results: The mean age of patients at the time of surgery was $70 \pm 10$ years. The mean uncorrected and corrected monocular distance visual acuity (VA) were LogMAR $0.06 \pm 0.10$ and LogMAR $0.00 \pm 0.08$, respectively. The outcomes for the binocular uncorrected distance visual acuity were almost the same ( $\log M A R-0.04 \pm 0.09)$. LogMAR $-010 \pm 0.15$ and $0.02 \pm 0.06$ were measured for the binocular uncorrected intermediate and near VA, respectively. The distancecorrected visual acuity was maintained in mesopic conditions. The contrast sensitivity was similar to that obtained after implantation of a bifocal intraocular lens and did not decrease in mesopic conditions. The binocular defocus curve confirms good VA even in the intermediate distance range, with a moderate decrease of less than LogMAR 0.2 at $-1.5 \mathrm{D}$, with respect to the best distance VA at $0 \mathrm{D}$ defocus. Patient satisfaction was high. No discrepancy between the objective and subjective outcomes was evidenced.

Conclusion: The introduction of a third focus in diffractive multifocal intraocular lenses improves the intermediate vision with minimal visual discomfort for the patient.

Keywords: lens implantation, trifocal diffractive intraocular lens, third focus, diffractive multifocal

\section{Introduction}

Multifocal lenses remain the best solution to achieve spectacle independence after cataract surgery. ${ }^{1}$ Two types of multifocal intraocular lenses (IOLs) are currently present on the market: refractive and diffractive. The optical function of the refractive IOLs derives from the refractive zones for distance and near vision allocated concentrically over the optic lens. The main disadvantage of this lens type is the significant pupildependence and the loss of energy in the transition zone. Diffractive IOLs use a diffractive pattern to create an additional focus for near vision in the first diffraction order. Although part of the incident light is intrinsically lost at higher orders of diffraction, studies have shown that the IOL offers good distance and near visual acuity (VA). It has
Correspondence: Jérôme C Vryghem Brussels Eye Doctors,

12-16 Boulevard

St-Michel, II 50 Brussels

(Woluwe St-Pierre), Belgium

Tel +3227416999

$\mathrm{Fax}+3227327148$

Email j.c.vryghem@vryghem.be 
also been reported that diffractive IOLs achieve better optical quality, based on optical bench measurements, than refractive multifocal IOLs. ${ }^{2}$ Publications presenting results from clinical studies indicate better contrast sensitivity after diffractive IOL implantation than for refractive multifocal IOL implantation for equivalent visual acuities. ${ }^{3}$

However, most studies also report poor scores for intermediate vision, correlating to worse intermediate visual acuity. ${ }^{4,5}$ It has also been reported that the implantation of bifocal diffractive IOLs leads to a higher percentage of spectacle-dependent patients, especially for intermediate distance vision.

More than 70 publications regarding multifocal IOLs have been published since 2010, according to a bibliographic search performed on http://www.pubmed.com, the online database of the American National Institute of Health. All of them are related to results obtained for bifocal IOLs, except the one on the multifocal IOL (MIOL)-Record (Reper-NN, Nizhegorodskaya, Russia). ${ }^{6}$

Hence, the quality of vision with multifocal IOLs is a real concern. In many cases, photic phenomena (glare, halos, positive or negative dysphotopsia) are described after multifocal lens implantation. ${ }^{7}$ Blurred vision is the primary reason for explantation. ${ }^{8}$ Most surgeons are demotivated to select multifocal implants due to the above-mentioned side effects, and due to the fact that available multifocal IOLs on the market do not cover the full range of vision and often have insufficient intermediate vision. ${ }^{9,10}$

A new trifocal IOL, the FineVision IOL (PhysIOL, Liège, Belgium), has become commercially available as of 2010 . The introduction of a third focal point in multifocal IOL optics is expected to enhance the VA in intermediate distance for patients who need sight in this range (eg, for computer work). A risk of an additional defocus image with trifocal diffractive IOLs exists compared to their bifocal counterparts and should be addressed with care. Theoretically, it might increase the number of patients with blurred vision due to two permanent defocus images.

A pilot study has been conducted over a prospective consecutive case series of the first 50 implantations with FineVision performed in Clinique Saint-Jean. The study presented here was designed to determine the clinical outcomes of the FineVision lens and to investigate the influence of the added intermediate vision on distance and reading.

\section{Material and methods Study design}

This prospective study comprises 50 eyes in 25 consecutive patients who had cataract surgery or refractive lens exchange with the bilateral implantation of the FineVision trifocal IOL between June 2010 and March 2011 at the Clinique Saint-Jean and the Brussels Eye Doctors Private Clinic in Brussels, Belgium. The guidelines of the Helsinki Declaration were followed, and informed consent was obtained from all patients.

\section{Intraocular lens}

The diffractive trifocal optic profile of the multifocal IOL FineVision (Figure 1) is applied on the platform of the IOL, Micro AY (PhysIOL, Liège, Belgium), with clinical outcomes since 2004. It has four closed haptics and is made of hydrophilic methacrylate with $25 \%$ water content at the equilibrium. FineVision efficiently filters hazardous ultraviolet and blue light. It has a biconvex and aspheric optic allowing for spherical aberrations of $-0.11 \mu \mathrm{m}$ at $5.0 \mathrm{~mm}$ aperture $\left(Z^{40}\right)$. Its optic diameter is $6.15 \mathrm{~mm}$, and its total diameter $10.75 \mathrm{~mm}$. The haptic angulation is $5^{\circ}$.

Detailed presentation of the trifocal IOL design of FineVision has been presented recently in a scientific publication by Gatinel et al. ${ }^{11}$ This lens combines two diffractive patterns, one adding +3.50 diopters (D) for the near vision and the other one +1.75

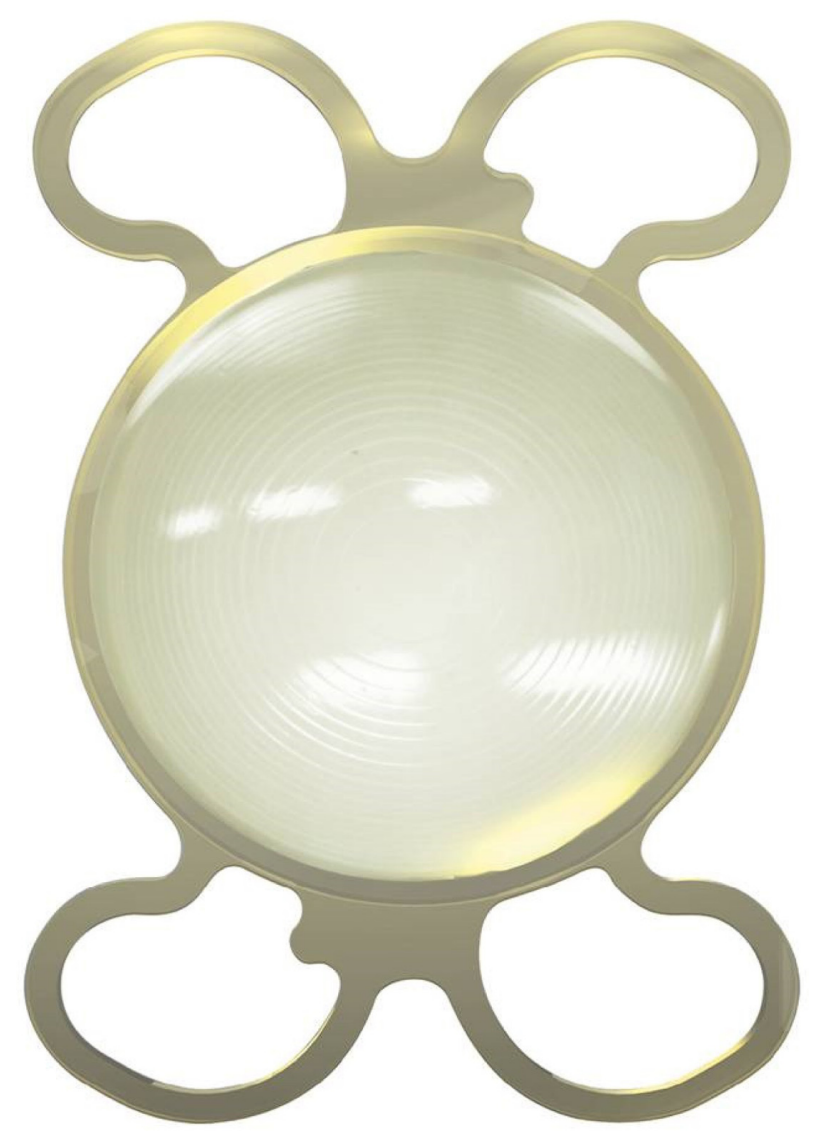

Figure I Image of the FineVision (PhysIOL, Liège, Belgium) intraocular lens. 
D for the intermediate vision. An asymmetric distribution of energy among the three foci (near, intermediate, and far) allows for dominant distance vision, improved intermediate vision, and nonimpacted near vision. The IOL is based on a fully diffractive optic with gradual attenuation of the diffractive step height throughout the entire optic, resulting in a continuous change of the light energy distribution directed to the three primary foci. When the pupil aperture becomes larger, the peripheral steps are progressively exposed, with increasing amounts of light dedicated to distance vision and less light to the near and intermediate focal points. This gradual decrease of the step height from center to periphery has been shown to reduce halos, which are generated by defocused light under dim conditions. ${ }^{12}$ The percentage of lost energy for typical bifocal diffractive IOLs is $18 \%-20 \%$, while it is approximately $15 \%$ for the IOL FineVision. This is due to accumulation of the energy from the second order of the diffractive pattern for the intermediate vision $(+1.75 \mathrm{D})$ to the energy from the first order of the diffractive pattern for the near vision (+3.50 D). Thus, the selection of this double-diffractive pattern saves energy which is used for near vision and if lost would increase the risk of blurred image. ${ }^{11}$

\section{Patient selection}

During the preoperative examination, VA was measured using a Snellen chart, intraocular pressure using a Goldmann tonometer, axial length and keratometric values using the IOLMaster 500 (Carl Zeiss Meditec, Jena, Germany). A slit lamp examination of the anterior segment and an indirect ophthalmoscopy were performed; ocular comorbidities (such as diabetic retinopathy, age-related macular degeneration, cornea guttata, or pseudoexfoliative syndrome) were exclusion criteria. Patients with corneal astigmatisms greater than $1.75 \mathrm{D}$ were not considered for inclusion in the study. The patient's expectations regarding spectacle independence and visual quality were also assessed.

\section{Surgical technique}

One surgeon performed the surgeries using a standard bimanual phaco-chop technique of sutureless microincision, phacoemulsification, and topical anesthesia. The IOL was inserted by docking the cartridge into the incision. Postoperative topical therapy included a combination of topical antibiotic and steroidal agents.

\section{Follow-up}

The patients were examined 6 months after surgery, and the following measurements were performed: slit lamp examination, intraocular pressure measurements, and VA measurements. All of the following were measured in monocular and binocular circumstances, and in photopic and mesopic conditions:

- Uncorrected distance VA at $4 \mathrm{~m}$

- Corrected distance VA at $4 \mathrm{~m}$

- Uncorrected intermediate VA acuity at $70 \mathrm{~cm}$

- Distance-corrected intermediate VA at $70 \mathrm{~cm}$

- Uncorrected near VA acuity at $35 \mathrm{~cm}$

- Distance-corrected near VA at $35 \mathrm{~cm}$.

Light conditions were fixed at 10 lux; mesopic conditions were fixed at 10 lux, and photopic conditions were fixed at $500 \mathrm{lux}\left(3 \mathrm{~cd} / \mathrm{m}^{2}\right.$ [candela per square meter] and $85 \mathrm{~cd} / \mathrm{m}^{2}$, respectively).

The VA was measured using a Snellen optotype for distance vision and a Parinaud optotype for near vision. The intermediate VA was assessed with a decimal scale at $70 \mathrm{~cm}$ with a near optotype calibrated for $35 \mathrm{~cm}$. Converting the decimal values of the measured VA into a LogMAR scale, the minimum angular resolution (MAR) is divided by 2 (which is the ratio between 70 and $35 \mathrm{~cm}$ ). This involves subtracting $\log (2)$ from the original converted decimal values into LogMAR values, $\log M A R=\log (1 /$ Decimals $)$.

The binocular defocus curve was established using a defocalization lens from $+4 \mathrm{D}$ to $-4 \mathrm{D}$ and the best correction for distance by increment of $0.5 \mathrm{D}$. Postoperative keratometry was performed to assess the surgically induced astigmatism using the Alpins Method. ${ }^{12}$ The contrast sensitivity test was performed under photopic $\left(85 \mathrm{~cd} / \mathrm{m}^{2}\right)$ and mesopic $\left(3 \mathrm{~cd} / \mathrm{m}^{2}\right)$ conditions using the CVS1000 contrast sensitivity test (VectorVision, Greenville, SC, USA). The patients were surveyed using the questionnaire listed in Table 1.

\section{Statistics}

The results are presented as the mean \pm standard deviation (SD) and were calculated using Excel worksheet 2007

Table I List of questions addressed to the patients I to 2 months after surgery

Would you undergo implantation with this lens type again?

How do you assess the quality of vision for watching TV, reading, and

doing needlework? (excellent/good/poor/very bad)

Do you have to use distance spectacles?

Do you have to use near spectacles? When?

Do you experience halos?

Do you experience glare?

Do you see ghost images?

Do you see double images?

Do you experience discoloration?

Do you have difficulty in transitioning from dark to light or the contrary? 
software (Microsoft Corporation, Redmond, WA, USA). All the statistical analyses were performed with the Microsoft Excel add-in software, Analyse-it Standard Edition (Analyse-it Software Ldt, Leeds, UK). The Shapiro-Wilk test was used to test the normality of the preoperative variables. The difference in VA in photopic and mesopic conditions was tested with the Wilcoxon signed-rank test. A $t$-test was used to compare the mean age of the patients spontaneously reporting seeing halos and those who were not. Differences were considered statistically significant when the $P$-value was less than 0.05 .

\section{Results}

Five patients were operated on for refractive lens extraction and the others for cataract surgery. The preoperative outcomes are listed in Table 2. Normality was achieved for all data $(P<0.05)$.

The VA outcomes are listed in Table 3 for monocular, and Table 4 for binocular, vision. The mean uncorrected distance visual acuity was $\operatorname{LogMAR} 0.06 \pm 0.09$, the mean uncorrected near VA was LogMAR 0.11 \pm 0.12 , and the mean uncorrected intermediate VA was LogMAR $0.05 \pm 0.19$.

The monocular corrected distance VA was assessed with a mean spherical equivalent of $0.10 \pm 0.37 \mathrm{D}$. Ninety percent of eyes had a spherical equivalent less than or equal to $\pm 0.5 \mathrm{D}$, and $100 \%$ had a spherical equivalent less than or equal to $\pm 1 \mathrm{D}$. Figure 2 shows the distribution of the spherical equivalent.

The near and intermediate, monocular and binocular, distance-corrected visual acuities (corrected nearVA and corrected intermediate VA, respectively) decreased in mesopic conditions $(P<0.05)$, whereas there was no significant difference in the monocular and binocular distance-corrected visual acuities between mesopic and photopic conditions $(P>0.05)$.

After 6 months, the surgically induced astigmatism calculated by the Alpins method was $0.10 \mathrm{D}$ at $-3^{\circ}$.

The binocular defocus curve with the distance correction is given in Figure 3. The objective outcomes from the defocus curve are consistent with the measured VA, especially for near and intermediate vision.

Table 2 Preoperative patient data

\begin{tabular}{lll}
\hline & Mean \pm SD & Range \\
\hline Preoperative visual acuity & LogMAR 0.16 \pm .18 & LogMAR 0.60 to \\
& LogMAR -0.18 \\
Axial length & $23.70 \pm 1.08 \mathrm{~mm}$ & $22.4 \mathrm{I}$ to $26.77 \mathrm{~mm}$ \\
IOL power & $20.42 \pm 3.45 \mathrm{D}$ & II to $27.5 \mathrm{D}$ \\
Keratometry readings & $43.21 \pm 1.39 \mathrm{D}$ & 40.38 to $45.25 \mathrm{D}$ \\
Corneal astigmatism & $0.63 \pm 0.44 \mathrm{D}$ & 0 to $1.75 \mathrm{D}$ \\
Age at surgery & $70.37 \pm 10.34$ years & 49 to 93 years \\
\hline
\end{tabular}

Abbreviations: IOL, intraocular lens; SD, standard deviation; D, diopters; MAR, minimum angular resolution.
The contrast sensitivities in photopic and mesopic conditions are given in Figure 4. There was no significant difference in the distance VA between photopic and mesopic conditions $(P>0.05)$.

A summary of the questionnaire answers regarding the photic phenomena is given in Figure 5. Twenty-four percent of the patients reported spontaneously seeing halos, $8 \%$ on inquiry, but halos were not seen by $68 \%$ of the patients. The population reporting halos was younger ( $66 \pm 6$ years) than those who did not see halos ( $72 \pm 9$ years) $(P<0.05)$. Nevertheless, the halos were not considered to be bothersome. The quality of vision was then assessed with respect to the preoperative condition. Ninety-two percent of patients would undergo implantation with the same IOL. Eight percent had no opinion, as they argued that they had no point of comparison. The quality of vision was estimated to be good for watching TV and book reading in $100 \%$ of cases and was good for needlework in $88 \%$ of cases. Spectacle independence was achieved for $100 \%$ of eyes for distance vision and for $80 \%$ for near vision. In the $20 \%$ of the patients requiring spectacles for near vision, half of them only needed their spectacles for very small characters.

\section{Discussion}

The purpose of the present pilot study was to analyze the objective and subjective outcomes after the implantation of a diffractive trifocal IOL, and to compare the clinical findings with the theoretical findings.

Randomized-controlled trials are considered to be the reference standard for assessing medical interventions, such as surgical implants. However, randomized-controlled trials may involve a number of limitations that affect their performance, ${ }^{13}$ such as ethical aspects in the process of randomization. ${ }^{14-16}$ Only one publication ${ }^{6}$ is available on the outcomes of the implantation of another diffractive trifocal MIOL, and the findings it details are not very encouraging. The optical principles of the MIOL are very different from the FineVision IOL; the former being made of concentric diffractive zones allocated to near, intermediate, and distance visions, combining diffractive and refractive IOL principles. There was no existing scientific evidence that would have ethically justified a randomized controlled trial with the FineVision IOL. Two publications ${ }^{17,18}$ about the FineVision lens are now available, which were not yet published at the time of this study.

This study is a consecutive case series of 50 eyes in compliance with the ISO 11979-7 standard guidelines, which 
Table 3 Monocular visual acuity scores

\begin{tabular}{llll}
\hline LogMAR & Mean \pm SD & $<$ LogMAR 0.3 & $<$ LogMAR 0.I \\
\hline Photopic & & & \\
Uncorrected distance visual acuity & $0.06 \pm 0.09$ & $100 \%$ & $80 \%$ \\
Uncorrected intermediate visual acuity & $0.05 \pm 0.19$ & $98 \%$ & $58 \%$ \\
Uncorrected near visual acuity & $0.11 \pm 0.12$ & $96 \%$ & $42 \%$ \\
Distance-corrected distance visual acuity & $0.00 \pm 0.08$ & $100 \%$ & $94 \%$ \\
Distance-corrected intermediate visual acuity & $0.06 \pm 0.19$ & $98 \%$ & $54 \%$ \\
Distance-corrected near visual acuity & $0.09 \pm 0.12$ & $96 \%$ & $52 \%$ \\
Mesopic & & & \\
Distance-corrected distance visual acuity & $0.00 \pm 0.08$ & $100 \%$ & $94 \%$ \\
Distance-corrected intermediate visual acuity & $0.35 \pm 0.27$ & $66 \%$ & $8 \%$ \\
Distance-corrected near visual acuity & $0.32 \pm 0.19$ & $62 \%$ & $12 \%$ \\
\hline
\end{tabular}

Abbreviations: SD, standard deviation; MAR, minimum angular resolution.

recommends a 50-case series for a new IOL. The studied cohort followed a normal distribution, and according to the central limit, the mean and standard deviation of these 50 eyes represent the broader population. However, this study is limited in the small number of patients and in the inclusion of both eyes. As a pilot study, it must not include too large a number of patients "in order to minimize exposure to the risks of a new IOL” (from NBN_EN_ISO standard 11979-7).

\section{Visual acuity}

The outcomes with the FineVision IOL (Table 3) are good for intermediate and near vision, and are similar to the outcomes of several studies on the implantation of multifocal IOLs that have been reported in a recent article from de Vries et al. ${ }^{19}$ Furthermore, the distance and near visual acuities are maintained with the trifocal IOL while enhancing the intermediate visual acuity. The distance vision is maintained in dim conditions, which is consistent with the optical bench results. ${ }^{11}$ For increased pupil diameter, more energy is being allocated to far vision, whereas for smaller pupil aperture, part of this energy becomes useful for intermediate and near vision.

\section{Spectacle independence}

The VA outcomes are confirmed by the percentage of spectacle independence, which is larger than any of those reported in other studies. ${ }^{19}$ Spectacle independence is achieved for $100 \%$ of eyes for distance vision and for $80 \%$ for near vision with the FineVision IOL. In the $20 \%$ of the patients requiring spectacles for near vision, half this number need them for very small characters only. The safety of the IOL, compared to typical bifocal diffractive IOL, is demonstrated by the maintained far and near vision. Indeed, spectacle independence is achieved in only $7.5 \%$ of patients implanted with a monofocal lens. ${ }^{19}$

\section{Subjective outcomes}

The ability to test functional tasks adds credibility to VA outcomes and may be more aligned with patient expectations. For example, a VA test does not assess whether a patient is able to comfortably read the newspaper or watch TV. No patients reported poor vision quality when watching TV or reading a book with the FineVision lens. As it has been noted, there is no consensus on which test should be taken to assess

Table 4 Binocular visual acuity scores

\begin{tabular}{lccc}
\hline LogMAR & Mean \pm SD & $<$ LogMAR 0.3 & $<$ LogMAR 0.I \\
\hline Photopic & & & $100 \%$ \\
Uncorrected distance visual acuity & $-0.04 \pm 0.09$ & $100 \%$ & $92 \%$ \\
Uncorrected intermediate visual acuity & $-0.10 \pm 0.15$ & $100 \%$ & $84 \%$ \\
Uncorrected near visual acuity & $0.02 \pm 0.06$ & $100 \%$ & $100 \%$ \\
Distance-corrected distance visual acuity & $-0.07 \pm 0.08$ & $100 \%$ & $96 \%$ \\
Distance-corrected intermediate visual acuity & $-0.13 \pm 0.14$ & $100 \%$ & $88 \%$ \\
Distance-corrected near visual acuity & $0.02 \pm 0.05$ & $100 \%$ & $100 \%$ \\
Mesopic & & & $38.9 \%$ \\
Distance-corrected distance visual acuity & $-0.06 \pm 0.10$ & $100 \%$ & $41.2 \%$ \\
Distance-corrected intermediate visual acuity & $0.12 \pm 0.17$ & $94.5 \%$ & $100 \%$ \\
Distance-corrected near visual acuity & $0.13 \pm 0.12$ & & \\
\hline
\end{tabular}

Abbreviations: SD, standard deviation; MAR, minimum angular resolution. 


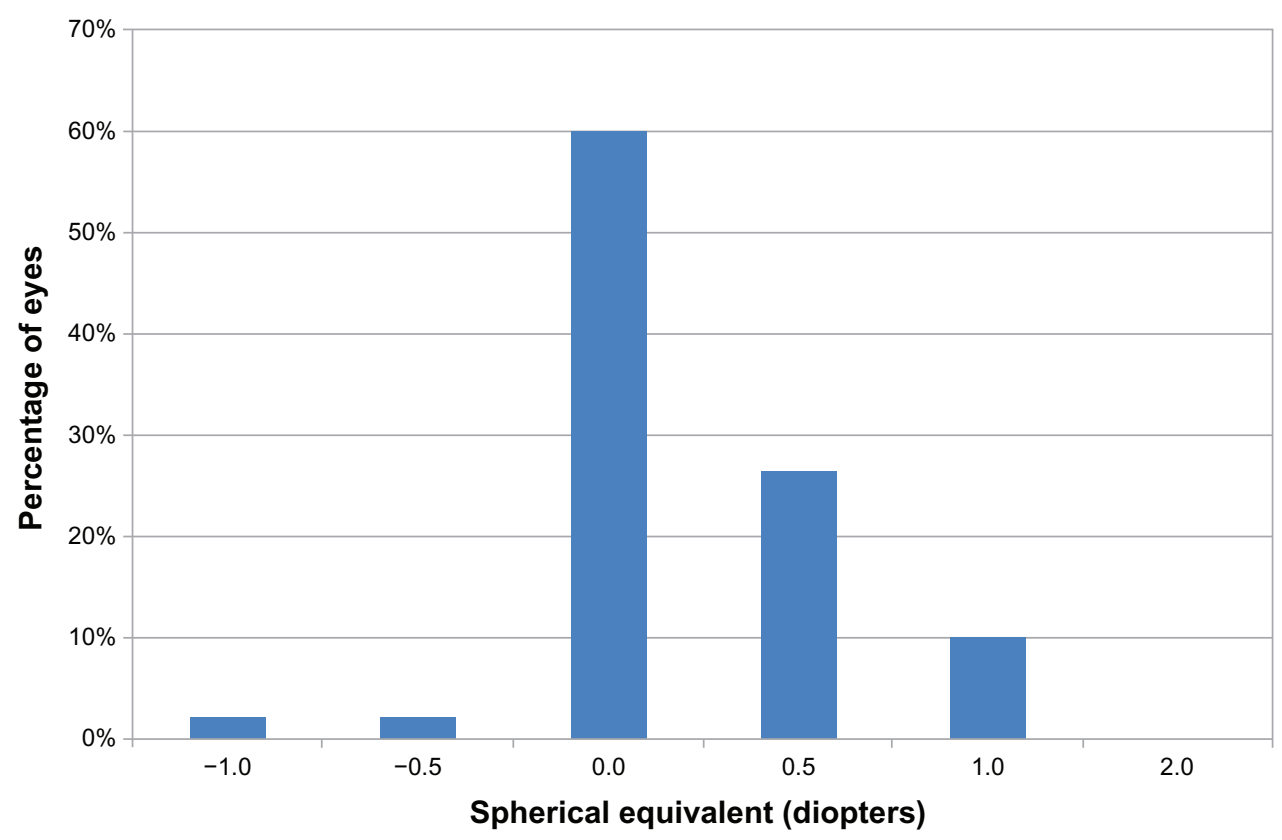

Figure 2 Distribution of the spherical equivalent: percentage of eyes with respect to the achieved spherical equivalent.

patient satisfaction. ${ }^{19}$ Yet the absence of complaint remains a good criterion for the surgeon.

\section{Contrast sensitivity}

Table 5 presents the mean logarithm of the contrast sensitivity $(\log C S)$ at 3 cycles per degree (cpd) and at $18 \mathrm{cpd}$ for different multifocal IOLs in photopic conditions. Except in the publication of Ferrer-Blasco et $\mathrm{al}^{20}$ whose cohort was made only of clear lens extractions and thus young patients, the $\log \mathrm{CS}$ is consistently in the same amplitude range between $3 \mathrm{cpd}$ and $18 \mathrm{cpd}$, and is similar to those results found with the FineVision in photopic conditions.

The important decrease in the $\log \mathrm{CS}$ with the Tecnis IOL (AMO, Santa Ana, CA, USA) ${ }^{21}$ or the Acrilisa IOL (Carl Zeiss Meditec $)^{22}$ in mesopic conditions was not observed in the present study for the FineVision IOL, similar to Restor

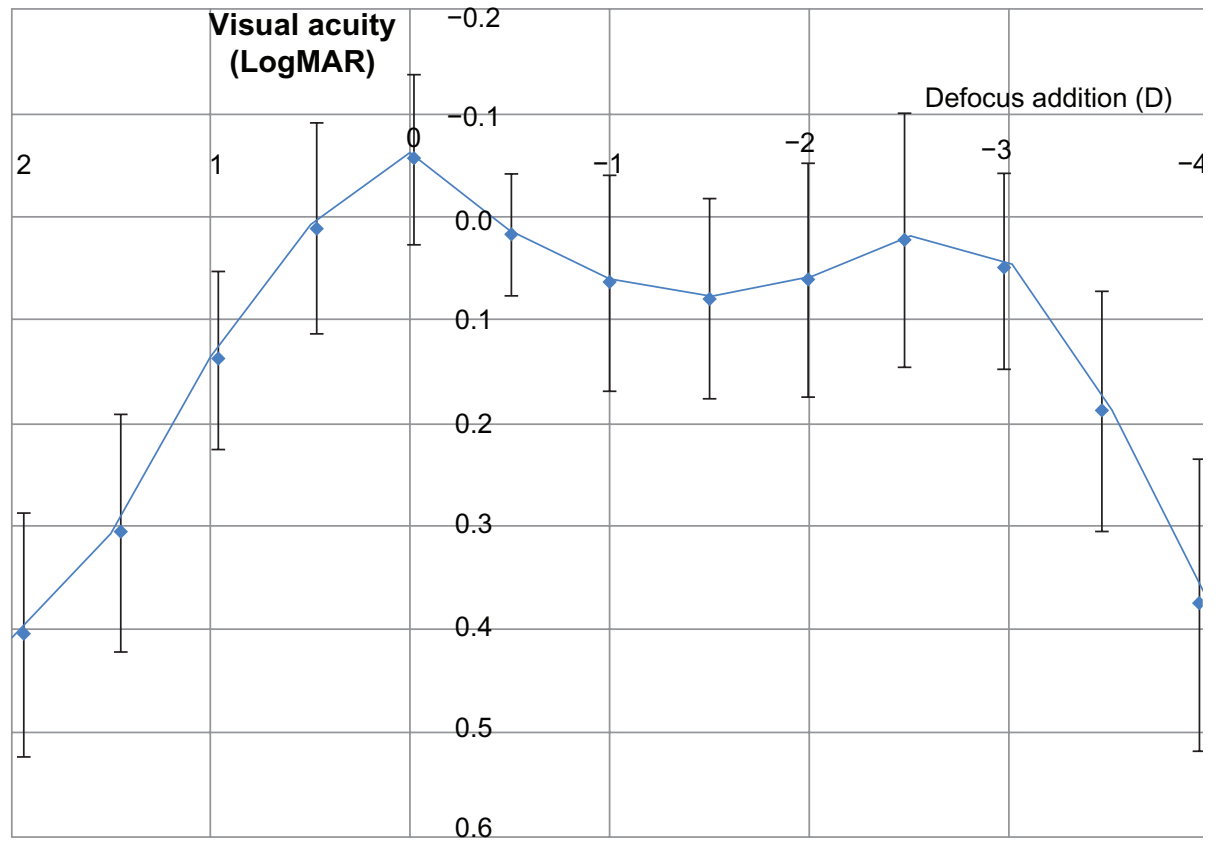

Figure 3 Average binocular defocus curve with distance correction. Abbreviations: MAR, minimum angular resolution; $D$, diopters. 


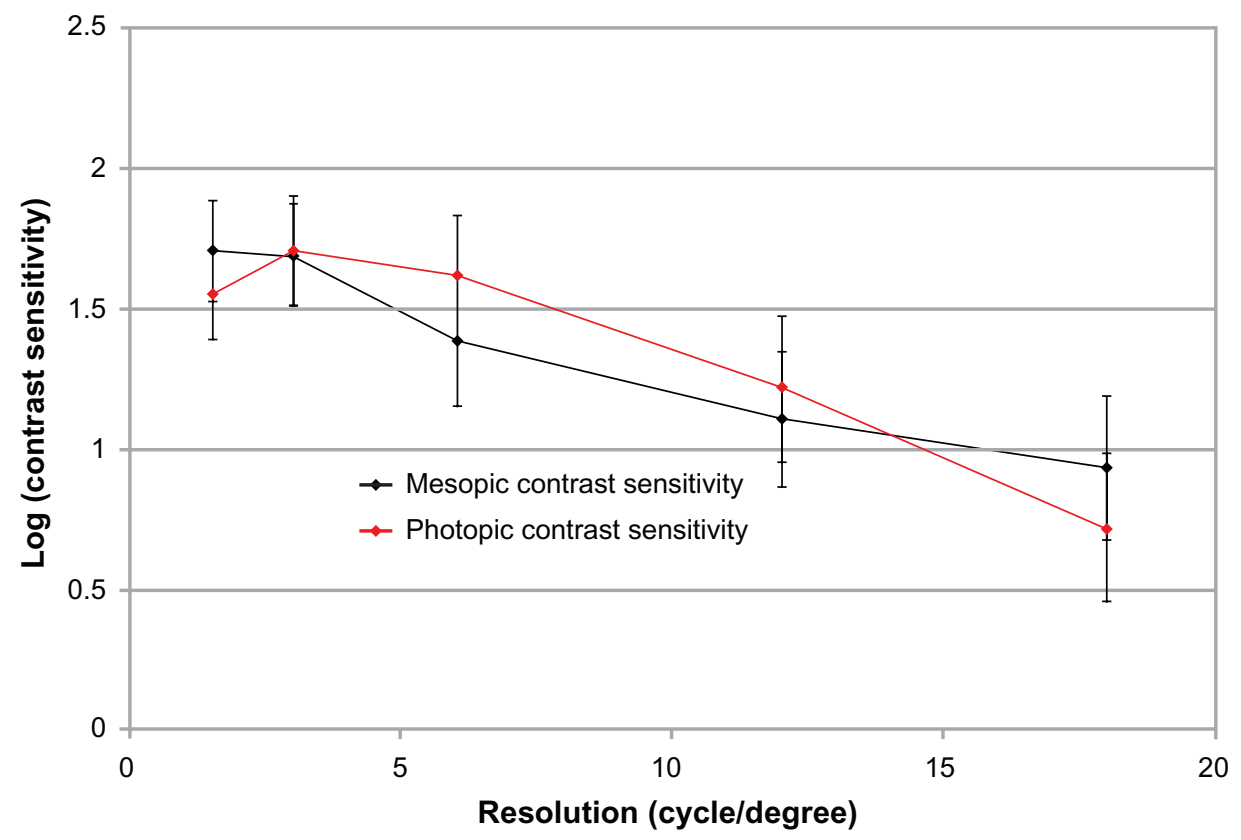

Figure 4 Monocular contrast sensitivity outcomes with CVS-1000 (VectorVision, Greenville, SC, USA) in photopic and mesopic conditions.

(Alcon Inc., Fort Worth, TX, USA). ${ }^{11}$ This is probably due to the fact that both FineVision and Restor had been designed with a gradual decrease of the diffractive step height from center to optic periphery, which allows the progression allocation of more light energy to the distance focus at larger pupils, favoring distance vision in dim conditions. ${ }^{11}$ In contrast, Tecnis and Acrilisa IOLs show constant diffractive step height on the entire optic with a constant light energy distribution between the near and far foci at different pupil size and lighting conditions.

\section{Defocus curve}

The Snellen and the Early Treatment Diabetic Retinopathy Study distance optotypes are standardized for any country.

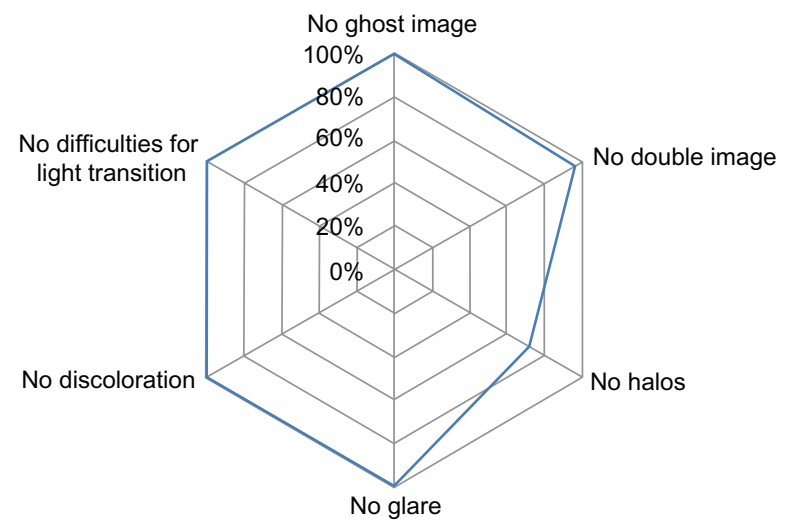

Figure 5 Scores obtained from the questionnaire addressed to the patients I to 2 months after surgery.
Contrary to a distance optotype, near vision tests, which are practical methods of assessing reading ability, do not provide a standardized measurement of near VA because the near chart position can vary from $25 \mathrm{~cm}$ to $40 \mathrm{~cm}$. Moreover, the font, font size, and character spacing of these near vision tests are different according to their country of origin (eg, Jaeger test, Parinaud test, Belgian reading test, Radner test, etc). The defocus test objectifies the intermediate and near vision ability because the error associated with the patient's position in respect to the reading distance during this test is negligible.

For the present study, a continuous defocus curve with a minimal decrease in the VA at the intermediate range was found. The binocular defocus curve confirms good VA even

Table 5 Mean logarithm of the contrast sensitivity in different publications for several multifocal IOLs

\begin{tabular}{|c|c|c|c|}
\hline Study & IOL type & $3 \mathrm{cpd}$ & $18 \mathrm{cpd}$ \\
\hline Present study & FineVision & 1.7 & 0.7 \\
\hline Voskresenskaya et $\mathrm{al}^{6}$ & MIOL record & 1.8 & 0.9 \\
\hline Ferrer-Blasco et $\mathrm{al}^{20}$ & $\begin{array}{l}\text { Acrysof Restor }+4 D \text { refractive } \\
\text { lens exchange }\end{array}$ & 2.1 & 1.5 \\
\hline Zelichowska et $\mathrm{al}^{30}$ & Acrysof Restor +4D & 1.5 & 1 \\
\hline Blaylock et $\mathrm{al}^{31}$ & Acrysof Restor Aspheric $+4 D$ & 2 & 1 \\
\hline de Vries et $a^{8,10}$ & Acrysof Restor Aspheric +4D & 1.7 & 0.6 \\
\hline de Vries et $a^{8,10}$ & Acrysof Restor Aspheric $+3 D$ & 1.7 & 0.6 \\
\hline Chang $^{32}$ & Acrysof Restor +4D & 1.84 & 0.95 \\
\hline Mester et $\mathrm{a}^{21}$ & Tecnis +4D & 1.7 & 0.7 \\
\hline Mesci et al ${ }^{33}$ & Tecnis +4D & 1.9 & 0.8 \\
\hline Alfonso et $\mathrm{al}^{29}$ & AcriLisa & 1.7 & 0.9 \\
\hline
\end{tabular}


in the intermediate distance range, with a moderate decrease of less than LogMAR 0.2 at a vergence of $-1.5 \mathrm{D}$ with respect to the best distance VA at $0 \mathrm{D}$ defocus.

We found outcomes that are consistent with the distance, intermediate, and near visual acuities measured with standard tests.

The binocular defocus curves for the Acrysof Restor Aspheric or Spherical, +3 D or +4D, ${ }^{9,10,23-26}$ Tecnis +4D (ZM900), ${ }^{26,27}$ Oculentis, ${ }^{28}$ and Acrilisa 366D lenses, ${ }^{9}$ all showed a drop in the VA of at least two lines at a vergence of $-1.5 \mathrm{D}$.

\section{Photic phenomena}

The study by de Vries et $\mathrm{al}^{8}$ showed that $38.2 \%$ of patients were dissatisfied after implantation of a multifocal IOL because they experienced major photic phenomena, with or without blurred vision. There is an important discrepancy between the reported rates of subjective photic phenomena. ${ }^{18}$ This discrepancy could be due to the explanations given to the patient by the surgeon to describe photic phenomena. Glare can be translated as sensitivity to light (dazzle) or as the sensation of a white veil in front of the actual image. Halos can also be explained in two ways: dazzle with light or rings around lights. The authors are aware that subjective inquiry is not optimal for the quantification of halos; proper halometry appears more convenient and should be considered in the future. Nevertheless, the trifocality of the FineVision lens does not appear to introduce any additional problems to those reported for diffractive bifocal MIOLs. This may be explained by the number of diffractive steps (26 steps) used in the FineVision IOL, which is lower than that for other diffractive IOLs (32 for the Tecnis and 28 for the Acrilisa), thus reducing the halos induced by the diffractive edges. In addition, FineVision shows convoluted diffractive steps, ie, with smoothed edges. Halos are therefore attenuated compared to more or less convoluted IOLs with sharp diffractive steps.

\section{Conclusion}

The FineVision trifocal diffractive IOL induces minimal photic phenomena (halos, glare) and provides good VA for distance, near, and intermediate vision, and thus good spectacle independence. No ghost images were reported, even with questioning. Intermediate vision was good when tested with the near visual chart as well as with a defocus addition of the defocus curve. Distance and near visual acuities were similar to those obtained with a bifocal IOL. The contrast sensitivity did not decrease upon dim conditions. As a pilot study, statistical analysis is limited to descriptive statistics. These outcomes are to be confirmed in the future with a randomized control trial built with the outcomes of this pilot study as criteria.

\section{Acknowledgments}

All surgeries were performed by Jérôme C Vryghem.

\section{Disclosure}

The authors report no financial or proprietary interests in this product, or any other conflict of interest.

\section{References}

1. Mesci C, Erbil H, Ozdoker L, Karakurt Y, Bilge AD. Visual acuity and contrast sensitivity function after accommodative and multifocal intraocular lens implantation. Eur J Ophthalmol. 2010;20(1): 90-100.

2. Maxwell WA, Lane SS, Zhou F. Performance of presbyopia-correcting intraocular lenses in distance optical bench tests. $J$ Cataract Refract Surg. 2009;35(1):166-171.

3. Mesci C, Erbil HH, Olgun A, Aydin N, Candemir B, Akçakaya AA. Differences in contrast sensitivity between monofocal, multifocal and accommodating intraocular lenses: long-term results. Clin Experiment Ophthalmol. 2010;38(8):768-777.

4. Cochener B, Lafuma A, Khoshnood B, Courouve L, Berdeaux G. Comparison of outcomes with multifocal intraocular lenses: a meta-analysis. Clin Ophthalmol. 2011;5:45-56.

5. Petermeier K, Messias A, Gekeler F, Szurman P. Effect of +3.00 diopter and +4.00 diopter additions in multifocal intraocular lenses on defocus profiles, patient satisfaction, and contrast sensitivity. $J$ Cataract Refract Surg. 2011;37(4):720-726.

6. Voskresenskaya A, Pozdeyeva N, Pashtaev N, Batkov Y, Treushnicov V, Cherednik V. Initial results of trifocal diffractive IOL implantation. Graefes Arch Clin Exp Ophthalmol. 2010;248(9):1299-1306.

7. Sood P, Woodward MA. Patient acceptability of the Tecnis multifocal intraocular lens. Clin Ophthalmol. 2011;5:403-410.

8. de Vries NE, Webers CA, Touwslager WR, et al. Dissatisfaction after implantation of multifocal intraocular lenses. J Cataract Refract Surg. 2011;37(5):859-865.

9. Alfonso JF, Fernández-Vega L, Puchades C, Montés-Micó R. Intermediate visual function with different multifocal intraocular lens models. J Cataract Refract Surg. 2010;36(5):733-739.

10. de Vries NE, Webers CA, Montés-Micó R, Ferrer-Blasco T, Nuijts RM. Visual outcomes after cataract surgery with implantation of a $+3.00 \mathrm{D}$ or $+4.00 \mathrm{D}$ aspheric diffractive multifocal intraocular lens: Comparative study. J Cataract Refract Surg. 2010;36(8):1316-1322.

11. Gatinel D, Pagnoulle C, Houbrechts Y, Gobin L. Design and qualification of a diffractive trifocal optical profile for intraocular lenses. J Cataract Refract Surg. 2011;37(11):2060-2067.

12. Alió JL, Agdeppa MC, Pongo VC, El Kady B. Microincision cataract surgery with toric intraocular lens implantation for correcting moderate and high astigmatism: pilot study. J Cataract Refract Surg. 2010; 36(1):44-52.

13. McCulloch P, Taylor I, Sasako M, Lovett B, Griffin D. Randomised trials in surgery: problems and possible solutions. BMJ. 2002; 324(7351):1448-1451.

14. Lilford RJ, Jackson J. Equipoise and the ethics of randomization. $J R$ Soc Med. 1995;88(10):552-559.

15. Schulz KF. Subverting randomization in controlled trials. JAMA. 1995;274(18):1456-1458.

16. Harbour R, Miller J. A new system for grading recommendations in evidence based guidelines. BMJ. 2001;323(7308):334-336. 
17. Cochener B, Vryghem JC, Rozot P, et al. Visual and refractive outcomes after implantation of a fully diffractive trifocal lens. Clin Ophthalmol. 2012;6:1421-1427.

18. Lesieur G. [Outcomes after implantation of a trifocal diffractive IOL.] J Fr Ophtalmol. 2012;35(5):338-342. French [with English abstract].

19. de Vries NE, Nuijts RM. Multifocal intraocular lenses in cataract surgery: literature review of benefits and side effects. J Cataract Refract Surg. 2013;39(2):268-278.

20. Ferrer-Blasco T, Montés-Micó R, Cerviño A, Alfonso JF, FernándezVega L. Contrast sensitivity after refractive lens exchange with diffractive multifocal intraocular lens implantation in hyperopic eyes. J Cataract Refract Surg. 2008;34(12):2043-2048.

21. Mester U, Hunold W, Wesendahl T, Kaymak H. Functional outcomes after implantation of Tecnis ZM900 and Array SA40 multifocal intraocular lenses. J Cataract Refract Surg. 2007;33(6):1033-1040.

22. Alió JL, Plaza-Puche AB, Piñero DP, et al. Optical analysis, reading performance, and quality-of-life evaluation after implantation of a diffractive multifocal intraocular lens. J Cataract Refract Surg. 2011; 37(1):27-37.

23. Petermeier K, Messias A, Gekeler F, Szurman P. Effect of +3.00 diopter and +4.00 diopter additions in multifocal intraocular lenses on defocus profiles, patient satisfaction, and contrast sensitivity. J Cataract Refract Surg. 2011;37(4):720-726.

24. Kohnen T, Nuijts R, Levy P, Haefliger E, Alfonso JF. Visual function after bilateral implantation of apodized diffractive aspheric multifocal intraocular lenses with a +3.0 D addition. J Cataract Refract Surg. 2009;35(12):2062-2069.

25. Alfonso JF, Puchades C, Fernández-Vega L, Montés-Micó R, Valcárcel B, Ferrer-Blasco T. Visual acuity comparison of 2 models of bifocal aspheric intraocular lenses. J Cataract Refract Surg. 2009; 35(4):672-676.
26. Toto L, Falconio G, Vecchiarino L, et al. Visual performance and biocompatibility of 2 multifocal diffractive IOLs: six-month comparative study. J Cataract Refract Surg. 2007;33(8):1419-1425.

27. Packer M, Chu YR, Waltz KL, et al. Evaluation of the aspheric tecnis multifocal intraocular lens: one-year results from the first cohort of the food and drug administration clinical trial. Am J Ophthalmol. 2010; 149(4):577-584

28. Van der Linden JW, van Velthoven M, van der Meulen I, Nieuwendaal C, Mourits M, Lapid-Gortzak R. Comparison of a new-generation sectorial addition multifocal intraocular lens and a diffractive apodized multifocal intraocular lens. J Cataract Refract Surg. 2012;38(1):68-73.

29. Alfonso JF, Fernández-Vega L, Señaris A, Montés-Micó R. Prospective study of the Acri.LISA bifocal intraocular lens. J Cataract Refract Surg. 2007;33(11):1930-1935.

30. Zelichowska B, Rekas M, Stankiewicz A, Cerviño A, Montés-Micó R. Apodized diffractive versus refractive multifocal intraocular lenses: optical and visual evaluation. J Cataract Refract Surg. 2008;34(12): 2036-2042.

31. Blaylock JF, Si Z, Vickers C. Visual and refractive status at different focal distances after implantation of the ReSTOR multifocal intraocular lens. J Cataract Refract Surg. 2006;32(9):1464-1473.

32. Chang DF. Prospective functional and clinical comparison of bilateral ReZoom and ReSTOR intraocular lenses in patients 70 years or younger. J Cataract Refract Surg. 2008;34(6):934-941.

33. Mesci C, Erbil HH, Olgun A, Aydin N, Candemir B, Akçakaya AA Differences in contrast sensitivity between monofocal, multifocal and accommodating intraocular lenses: long-term results. Clin Experiment Ophthalmol. 2010;38(8):768-777.
Clinical Ophthalmology

\section{Publish your work in this journal}

Clinical Ophthalmology is an international, peer-reviewed journal covering all subspecialties within ophthalmology. Key topics include: Optometry; Visual science; Pharmacology and drug therapy in eye diseases; Basic Sciences; Primary and Secondary eye care; Patien Safety and Quality of Care Improvements. This journal is indexed on

Submit your manuscript here: http://www.dovepress.com/clinical-ophthalmology-journal

\section{Dovepress}

PubMed Central and CAS, and is the official journal of The Society of Clinical Ophthalmology (SCO). The manuscript management system is completely online and includes a very quick and fair peer-review system, which is all easy to use. Visit http://www.dovepress.com/ testimonials.php to read real quotes from published authors. 